\title{
Knowledge, Attitude and Opinion of Drug Misuse and Abuse by Pharmacy Students: A Cross-Sectional Study in Jordan
}

\author{
Deema Jaber, Nailya Bulatova, Maysa Suyagh, Al-Motassem Yousef and \\ Mayyada Wazaify* \\ Department of Biopharmaceutics and Clinical Pharmacy, Faculty of Pharmacy, University of Jordan, Amman, Jordan
}

*For correspondence: Email: m.wazaify@ju.edu.jo; Tel: +962-795494923; Fax: +962-6-5300250

Received: 18 April 2015

Revised accepted: 9 July 2015

\begin{abstract}
Purpose: To assess the knowledge, attitude and opinion of final-year undergraduate and postgraduate pharmacy students regarding inappropriate drug use in a university campus, Amman, Jordan.

Methods: A cross-sectional survey using a self-completed validated anonymous questionnaire that consisted of two parts was adopted. The first part of the questionnaire pertained to respondents' demographic details, education level and any experience they might have had with drug misuse or abuse. The second part described students' knowledge, attitude and practice regarding the identification, prevention and management of drug misuse and abuse.

Results: $A$ total number of 198 pharmacy students filled the questionnaire ( $N=131$ undergraduate, and $N=67$ postgraduate students). A majority of the students strongly agreed/agreed that all pharmacy staff must be trained on recognizing drug abusers (92.0\%), informed of the kinds of drugs abused in the local area of the pharmacy (93.4\%) and trained on methods of dealing with drug abusers (92.6\%).

Conclusion: There is a need to implement a well-structured training on the identification, prevention and management of prescription and OTC drug misuse and abuse in undergraduate pharmacy curricula in Jordan. Modules should be updated regularly and tailored to meet the needs of pharmacy practice.
\end{abstract}

Keywords: Drug abuse and misuse, Knowledge, Attitude, Pharmacy curriculum

Tropical Journal of Pharmaceutical Research is indexed by Science Citation Index (SciSearch), Scopus, International Pharmaceutical Abstract, Chemical Abstracts, Embase, Index Copernicus, EBSCO, African Index Medicus, JournalSeek, Journal Citation Reports/Science Edition, Directory of Open Access Journals (DOAJ), African Journal Online, Bioline International, Open-J-Gate and Pharmacy Abstracts

\section{INTRODUCTION}

Inappropriate use of drugs of all kinds and by different age groups is a growing public health problem worldwide [1,2]. Inappropriate use of drugs can be classified into either 'abuse'; typically defined as use of a medication for nonmedical purpose (i.e., experience a mind altering effect) [3,4], or 'misuse'; which is the use of medications for a legitimate medical reason, yet in ways other than as directed, in most cases by alteration of either dose or duration of use $[3,4]$. While the terms 'abuse' and 'misuse' are used interchangeably when talking about illicit drugs, differentiation between them becomes more important when talking about prescription or over-the counter (OTC) medications.

Research has shown that opioid analgesics, stimulants, psychotherapeutic drugs, antihistamines, stimulant laxatives and sympathomimetics were among the most widely misused and abused prescribed and OTC medications [5-8]. 
The United States National Institute on Drug Abuse (NIDA) in 2011 estimated that approximately $2.8 \%$ of the population was using psychotherapeutic drugs for nonmedical purposes [9]. Similar results were confirmed by many researchers through the Middle East area $[2,8,10]$. Moreover, a number of studies in Jordan have highlighted the misuse and self-medication by systemic antibiotics [2,11-13]. Many reports showed an increase in the prevalence of prescription drug abuse [14-16]. Therefore, there is always a need for pharmacists to have the confidence and ability to offer psychosocial and medication recommendations to patients and other health care professionals about addictionrelated issues and their associated hazards, particularly because of the difficulties involved in recognizing addiction [14-16].

To the best of the authors' knowledge, relatively little research attention has focused on pharmacy students' knowledge, attitude and practice towards the inappropriate use of medications $[17,18]$. Therefore, the aim of this study to assess pharmacy students' knowledge about drug misuse and abuse, explore their attitudes and practice with regard to the most commonly suspected misused and abused groups of drugs.

The specific objectives of the study were:

1) To investigate the level of knowledge of pharmacy students about: the terminology of, reasons behind, pattern of and prevalence of drug misuse and abuse.

2) To explore students' attitude, experience and expectations of pharmacy curricula regarding the issue of drug abuse/misuse.

3) To describe the ability of students to recognize suspected drug abusers and/or misusers in the pharmacy and their potential suggestions and willingness to deal with the problem.

4) To explore their opinion on currently implemented strategies to reduce drug misuse, and ask them to suggest new strategies to reduce this problem.

\section{EXPERIMENTAL}

This study adopted a cross-sectional survey methodology using a self-completed validated anonymous questionnaire. The questionnaire was adopted from Hughes et al and modified to be applicable in Jordan [3]. The instrument was translated to Arabic and then back-translated to English in order to assure validity. Every effort was made during literature review to ensure content validity. Moreover, various drafts of the questionnaire were evaluated individually by two clinical pharmacists, one statistician and one sociologist in order to ensure face validity.

The University of Jordan is the largest and oldest university in the country; notably, only students with the highest grades could be accepted into the programs of Healthcare specialties (Medicine, Pharmacy, Dentistry and Rehabilitation) in Jordanian universities. Thus, it is thought that UJ students' background, skills, and abilities may be a good representation of those of pharmacy students in Jordan.

The study was piloted on 5 undergraduate and 5 postgraduate students before the official start of the definitive study. Few questions were added/deleted accordingly and the data of the pilot part were excluded from the final analysis.

A simple random sample of 3 modules for final year undergraduate students $(\mathrm{N}=165)$ was used to recruit respondents, whereas the questionnaire was distributed to all postgraduate students $(\mathrm{N}=70)$ in the faculty. The study was carried out after the end of each selected lecture, when questionnaires were distributed and then collected after completion. The questionnaire was distributed to all final year students in the randomly picked modules using a 'drop and pick' (after obtaining verbal informed consent of the student to participate in the study and permission of the module lecturer to take 15 minutes at the end of the lecture). Students were assured that all the information provided by them is confidential and will be used only for research purposes by the team at the University of Jordan (UJ).

The questionnaire consisted of two parts: The first part, described respondents' demographic details such as age, gender, level of education (postgraduate or undergraduate). They were also asked if they had witnessed any member of their family/friends having a history of substance misuse/abuse problems. Students were asked if they have ever attended any training courses on drug misuse/abuse during their 5-6 year pharmacy study period.

In the second part, pharmacy students were asked to answer some questions about their attitudes, opinions and practice (if postgraduate and had work experience) towards the 
prevention, identification and management of the problem of drug misuse and abuse.

\section{Statistical analysis}

Data were coded and entered into a customdesigned SPSSC) (Version 17.0) database for statistical analysis. Descriptive measures presented included frequencies, percentages and corresponding $95 \%$ confidence intervals (Cls). $\mathrm{X}^{2}$ - square and Fisher exact tests were used to test for statistical difference present among variables $(p<0.05)$.

\section{RESULTS}

A total number of 198 pharmacy students responded and filled the questionnaire $(N=131$ undergraduate, and $\mathrm{N}=67$ postgraduate students). The majority of respondents (76.8\%) were female and undergraduate students (66.2 $\%)$. The average age of respondents was 23.76 $( \pm 3.58)$.

With regard to students' experience of drug problem among families/friends, a little more than one-quarter of students $(27.3 \%)$ reported to have family/friends with substance misuse problems. The majority of students (63.6\%) reported that they had received training about drug misuse and abuse during their pharmacy studying years. These data are presented in Table 1.

On the 5 point Likert scale, the majority of students agreed/strongly agreed $(\mathrm{N}=186,93.3$ $\%$ ) that it is suitable for a pharmacist to advise suspected drug misusers (in a written or verbal form) about the risks or the way of treating the risks of their behavior, whereas $77.3 \%$ stated to be willing to do that. More than a third of respondents (35.4\%) agreed/strongly agreed that dispensing controlled dugs without a medical recipe is an important source of money for the pharmacy. Females were more likely to consider themselves more suitable to provide such advice than males $(p=0.02)$. Students younger than 24 years were more willing to advise suspected drug misusers and abusers about the risks of their behavior than their older counterparts $(p<$ 0.0001). Undergraduate students more frequently strongly agreed/agreed than postgraduate ones that dispensing controlled drugs without a medical prescription is an important source of money for the pharmacy ( $p=$ 0.015). The attitudes and opinions of respondents are summarized in Tables 2(a) and 2(b).

Students were asked whether they had been able to identify suspected drug misusers and abusers during their training in community pharmacy (if undergraduate) or during their work experience (if postgraduate). The most commonly reported methods were strong and persistent request for the controlled drug (37.4 $\%)$ followed by the use of drugs outside the guidelines $(26.3 \%)$. More results are presented in Table 3.

As demonstrated in Table 4, $23.2 \%$ of students would advise drug misusers and abusers about the expected ADR associated with certain drugs, and $24.2 \%$ of them would suggest safer alternatives.

In the part of the questionnaire that asked about pharmacy students' opinions about the strategies used to reduce drug misuse and abuse, the majority of students strongly agreed/agreed with

Table 1: Experience of participating students regarding the problem of drug misuse/abuse $(\mathrm{N}=198)$

\begin{tabular}{ll}
\hline Variable & N (\%) \\
\hline Do you have any friends or relatives who faced problems in using drugs & $54(27.3)$ \\
Yes & $138(69.7)$ \\
No & \\
Have you ever received training about drug misuse at the Faculty of Pharmacy \\
$\quad$ Yes & $67(33.8)$ \\
No & $126(63.6)$ \\
Have you had any course about drug abuse during your study & \\
Yes & $79(39.9)$ \\
No & $116(58.6)$ \\
Do you like to receive training on drug misuse in the future & $157(79.3)$ \\
Yes & $31(15.7)$ \\
No &
\end{tabular}


Table 2(a): Knowledge and attitudes of respondents towards misuse and abuse of drugs in community pharmacy $(\mathrm{N}=198)$

\begin{tabular}{|c|c|c|c|}
\hline Variable & $\mathbf{N}=198$ & $P$-value & Comment \\
\hline $\begin{array}{l}\text { Do you know the difference between } \\
\text { the terms 'drug abuse' and 'misuse' } \\
\text { Yes } \\
\text { No }\end{array}$ & $\begin{array}{l}153(77.3 \%) \\
41(20.7 \%)\end{array}$ & $\begin{array}{l}\text { Males } \\
\text { Females }\end{array}$ & $\begin{array}{l}\text { Females more frequently } \\
\text { considered themselves } \\
\text { knowledgeable regarding the } \\
\text { difference between the terms } \\
\text { 'abuse' and 'misuse' than } \\
\text { males }\end{array}$ \\
\hline $\begin{array}{l}\text { It is suitable to advise suspected drug } \\
\text { misusers (in a written or verbal form) in } \\
\text { a pharmacy about the risks or the way } \\
\text { of treating the risks of their behavior }\end{array}$ & & 0.022 & $\begin{array}{l}\text { Females were more likely to } \\
\text { consider themselves more } \\
\text { suitable to provide such } \\
\text { advice than males }\end{array}$ \\
\hline $\begin{array}{l}\text { Strongly agree/Agree } \\
\text { Strongly disagree/Disagree } \\
\text { Not Sure }\end{array}$ & $\begin{array}{l}186(93.9 \%) \\
3.0(1.5 \%) \\
3.0(1.5 \%)\end{array}$ & $\begin{array}{l}\text { Males } \\
\text { Females }\end{array}$ & \\
\hline $\begin{array}{l}\text { I am willing to advise suspected drug } \\
\text { misusers (in a written or verbal form) } \\
\text { about the risk or the way of treating the } \\
\text { risks of their behavior } \\
\text { Strongly agree/Agree } \\
\text { Strongly disagree/Disagree } \\
\text { Not sure }\end{array}$ & $\begin{array}{l}153(77.3 \%) \\
10(5.0 \%) \\
35(17.7 \%)\end{array}$ & $\begin{array}{l}<0.0001 \\
<24 \text { yrs vs } \\
\text { older students }\end{array}$ & $\begin{array}{l}\text { Students younger than } 24 \\
\text { years are more willing to } \\
\text { advise suspected drug } \\
\text { misusers and abusers about } \\
\text { the risks of their behavior than } \\
\text { their older counterparts }\end{array}$ \\
\hline
\end{tabular}

Table 2(b): Beliefs of respondents towards misuse and abuse of drugs in community pharmacy $(\mathrm{N}=198)$

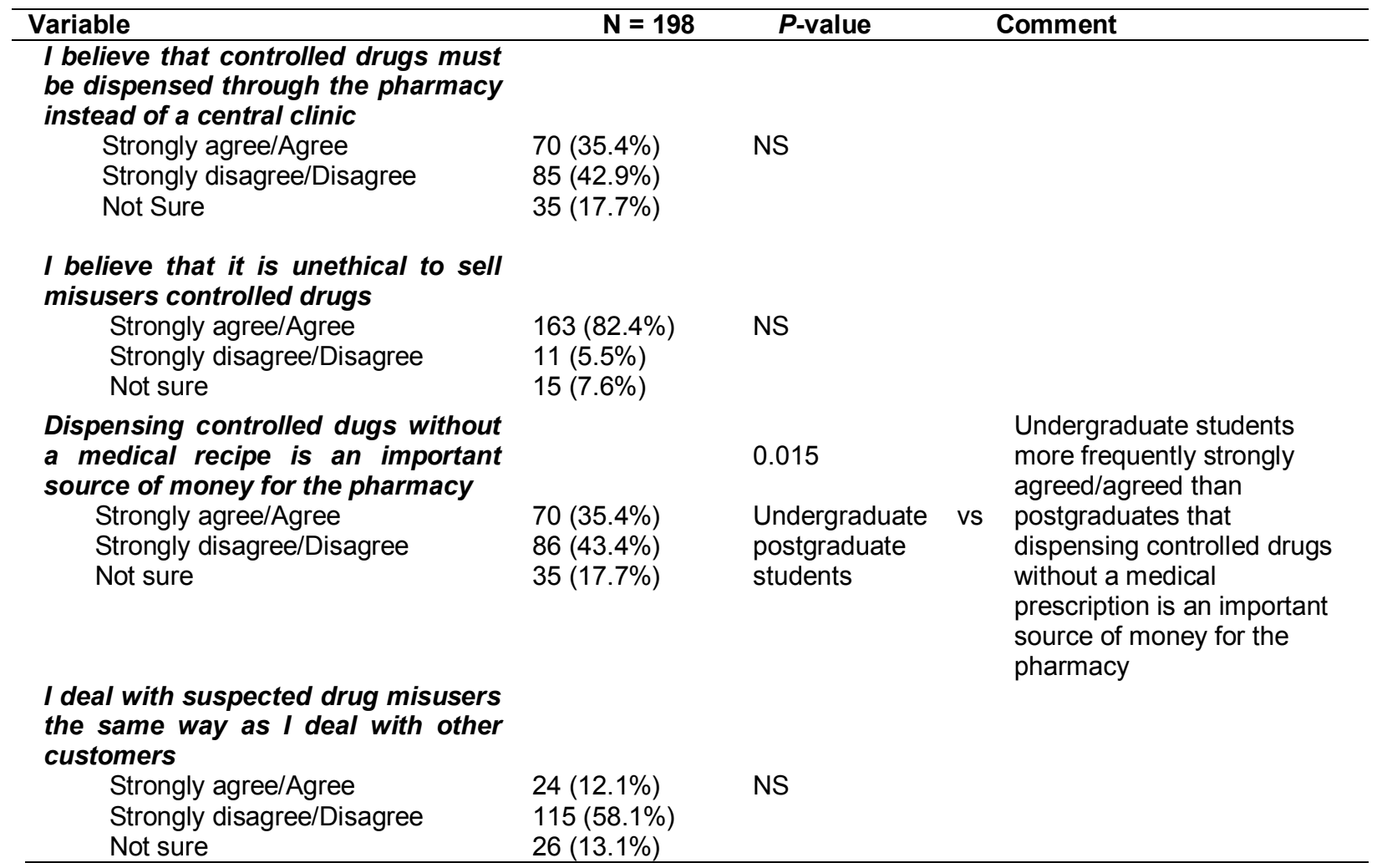

NS $=$ No statistical significance

Table 3: Reported methods of identifying suspected drug misusers and abusers in community pharmacy $(\mathrm{N}=$ 198)

\begin{tabular}{cc}
\hline How can you suspect drugs misusers and abusers? & N (\%) \\
\hline Strong and persistent request for the controlled drug & $74(37.4)$ \\
Report of lost or stolen supply of the prescribed drug & $38(19.2)$ \\
Report of a controlled substance as the only effective one & $46(23.2)$ \\
Using the drug outside its guidelines of use & $52(26.3)$ \\
\hline
\end{tabular}


the suggestions that all pharmacy staff must be trained on recognizing drug abusers (92.0 $\%$ ), informed of the kinds of drugs abused in the local area of the pharmacy (93.4\%), trained on methods of dealing with drug abusers (92.6\%), informed of drugs liable to abuse (90.4\%), and $76.2 \%$ of them suggested that all suspected abusers should be referred to a physician as summarized in Tables $5 a$ and $5 b$.

In addition, while asking about their opinions in some suggested solutions that may be effective in solving the problem of drug abuse in the pharmacy, $28.3 \%$ of students think that raising public awareness about this problem through media, and $23.7 \%$ of students think that assigning a responsible authority to monitor pharmacists are useful solutions to reduce drug misuse and abuse problems. Lastly, $77.8 \%$ of the students expressed that they were confident about their answers as shown in Table 5.

\section{DISCUSSION}

Overall, this study revealed a strong inclination of pharmacy undergraduate and postgraduate students at $U J$ to receive more training about the identification and management of the problem of drug misuse and abuse, despite reporting the reception of some information scattered in different modules.

Table 4: Suggested strategies by respondents to reduce drug misuse/abuse in community pharmacies $(\mathrm{N}=198)$

\begin{tabular}{ll}
\hline Variable & N (\%) \\
\hline I warn/advise patients about the expected ADR associated with certain drugs & $46(23.2)$ \\
$\quad$ Yes & $4(2.0)$ \\
No & \\
I suggest safer alternatives for the abused drug & $48(24.2)$ \\
$\quad$ Yes & $6(3.0)$ \\
No & \\
Do you call nearby pharmacies to inform them about a suspected abuser? & $23(11.6)$ \\
Yes & $35(17.7)$ \\
No & \\
\hline
\end{tabular}

Table 5(a): Opinions of respondents on strategies used to reduce drug misuse and abuse in community pharmacy $(\mathrm{N}=198)$

\begin{tabular}{|c|c|}
\hline Variable & $\mathrm{N}(\%)$ \\
\hline \multicolumn{2}{|c|}{$\begin{array}{l}\text { How would you rate the level of control over drugs by official authorities in the } \\
\text { pharmacy you have been trained or working in? }\end{array}$} \\
\hline Strongly controlled & $17(8.6)$ \\
\hline Controlled to some extent & $26(13.1)$ \\
\hline Badly controlled & $15(7.6)$ \\
\hline \multicolumn{2}{|c|}{ All pharmacy staff must be trained on recognizing drug abusers } \\
\hline Strongly agree/Agree & $182(92.0)$ \\
\hline Strongly disagree/Disagree & $2(1.0)$ \\
\hline Not Sure & $3(1.5)$ \\
\hline \multicolumn{2}{|c|}{$\begin{array}{l}\text { All pharmacy staff must be informed of the kinds of drugs abused in the local } \\
\text { area of the pharmacy }\end{array}$} \\
\hline Strongly agree/Agree & $185(93.4)$ \\
\hline Strongly disagree/Disagree & $1(0.5)$ \\
\hline Not Sure & $1(0.5)$ \\
\hline \multicolumn{2}{|c|}{ All staff should be trained on methods of dealing with drug abusers } \\
\hline Strongly agree/Agree & $184(92.6)$ \\
\hline Strongly disagree/Disagree & $2(1.0)$ \\
\hline Not Sure & $2(1.0)$ \\
\hline \multicolumn{2}{|c|}{ All staff should be informed of drugs liable to abuse } \\
\hline Strongly agree/Agree & $179(90.4)$ \\
\hline Strongly disagree/Disagree & $4(2.0)$ \\
\hline Not Sure & $3(1.5)$ \\
\hline \multicolumn{2}{|c|}{ All suspected abusers should be referred to a physician } \\
\hline Strongly agree/Agree & $151(76.2)$ \\
\hline Strongly disagree/Disagree & $10(5.0)$ \\
\hline Not Sure & $25(12.6)$ \\
\hline
\end{tabular}


Table 5(b): Opinions of respondents on strategies used to reduce drug misuse and abuse in community pharmacy $(\mathrm{N}=198)$

\begin{tabular}{|c|c|}
\hline Variable & $\mathbf{N}(\%)$ \\
\hline \multicolumn{2}{|c|}{$\begin{array}{l}\text { Pharmacists should cooperate with each other and with all other members of the } \\
\text { medical team in dispensing some kinds of drugs }\end{array}$} \\
\hline Strongly agree/Agree & $144(72.7)$ \\
\hline Strongly disagree/Disagree & $17(8.6)$ \\
\hline Not Sure & $24(12.1)$ \\
\hline \multicolumn{2}{|c|}{ Pharmacists should not sell drugs to people who appear to abuse those drugs } \\
\hline Strongly agree/Agree & $135(68.2)$ \\
\hline Strongly disagree/Disagree & $19(9.6)$ \\
\hline Not Sure & $33(16.7)$ \\
\hline \multicolumn{2}{|c|}{$\begin{array}{l}\text { Do you think that some OTC drugs must be reclassified to prescription-only } \\
\text { status }\end{array}$} \\
\hline Yes & $57(28.8)$ \\
\hline No & $122(61.6)$ \\
\hline \multicolumn{2}{|c|}{ Do you think that some OTC drugs can be sold outside pharmacies } \\
\hline Yes & $29(14.6)$ \\
\hline No & $145(73.2)$ \\
\hline \multicolumn{2}{|c|}{ How much are you confident in answering this questionnaire } \\
\hline Confident & $154(77.8)$ \\
\hline Some doubts & $23(11.6)$ \\
\hline Unconfident & $5(2.5)$ \\
\hline
\end{tabular}

In fact, many pharmacy students do not receive during their study the effective training in the drug misuse and abuse and in the management of patients with dependence and addiction problems, although curricular guidelines have long been established to address drug misuse and abuse education as a mandatory course in pharmacy schools [19].

In Jordan the majority of pharmacists (approximately $93 \%$ ) work in community pharmacies which are considered the most accessible primary health care facilities with over 2000 registered pharmacies distributed throughout the country [11]. This fact has contributed to the responsibility of community pharmacists towards the controlled drug supply to the public, in addition to the prevention, identification and management of prescription and OTC drug abuse and misuse in their pharmacies $[20,21]$.

Of the notable results that the majority of students had mentioned was the suitability to advise suspected drug misusers/abusers in pharmacies about the risk of drug misuse/abuse. This may be easier said than applied since a less proportion said that they would be ready to do it. This fact can be explained by the fact that many drug-seeking individuals can be perceived as "dangerous" people and sometimes may carry weapons or cause trouble in the pharmacy, the fact that may deter pharmacists from wanting to engage in confrontation. Threatening and violent incidents in community pharmacies has been reported in a study done by [22], where the participant pharmacists reported effects on their general dispensing and advice-giving activities due to the lack of security and safety specially at late-night shifts. According to the Pharmacists' Defense Association in the United Kingdom, dealing with the risk of violent and abusive behavior should be a major part of the policies and procedures of pharmacy practice. In addition, appropriate policies and procedures will considerably reduce risk, such as installing safety screens where staff is most at risk, providing personal attack alarms for high risk staff, employing security staff in serious situations, and providing special training for pharmacists on how to deal with suspected abusers [23].

One of the results that may raise a question regarding the ethical frame students have regarding the dispensing of controlled drugs is that $34.4 \%$ of respondents strongly agreed/agreed that dispensing controlled dugs without a medical recipe was an important source of money for the pharmacy, while $17.1 \%$ of respondents were "unsure". Albsoul-Younes et al mentioned in their survey that according to the Jordanian Drug and Pharmacy Practice Law since 1972 that inspectors from the Ministry of Health $(\mathrm{MOH})$ frequently visit community pharmacies to check any violation in general and check special prescriptions for medicines, such as opioids, opioid derivatives, or opioidcontaining preparations classified as Schedules $1-4$ drugs, for which the pharmacist is required to keep the record of these special prescriptions for $\mathrm{MOH}$ inspection. As such, it is a rare 
incidence for a community pharmacy to sell such products [2].

Benzodiazepines (with the exception of alprazolam), barbiturates and some psychotherapeutics agents, however, are classified in Schedule 8 where the law does not require the pharmacist to keep record of such prescriptions and aborts the chance to trace any violation and allows some pharmacists to sell such preparations without a prescription [2]. Again, this appeared in $13.1 \%$ respondents who either disagreed/strongly disagreed or were unsure that it was unethical to sell controlled drugs to suspected misusers/abusers. Part of the problem is cultural as the uncontrolled consumption and monitoring of consumption of medicines in Jordan is one reason of confusion among responding students. This practice has also been reported in other Arab countries like Egypt, Kuwait, and Palestine [10,24,25].

Haddad et al surveyed a 400 high school students of both gender in Irbid, a large urban city at the north of Jordan, only to find that the students lacked in-depth knowledge of substance abuse [26].

More than half of respondents said that they deal with suspected drug misusers different from the way they deal with other customers. This can either be due to the fact that students are usually taught to deal with suspected misusers/abusers as patients who need help rather than criminals OR, on the contrary, because they fear suspects, threat of harm, especially in case of female or novice pharmacists [2].

\section{Limitations of the study}

In Jordan, the postal system is not reliable. The authors had to use hand delivery for the questionnaire and obtained the required information with the aid of research assistants. Although this was reflected in the high response rate, it could have affected the tendency of pharmacy students to report freely. It is also recognized that most of the data are based on students' perceptions of day-to-day events, which is highly subjective and captures only a single point of view.

\section{CONCLUSION}

There is a need to implement a well-structured training on the identification, prevention and management of prescription and OTC drug misuse and abuse in university pharmacy curricula. Although, there are some topics scattered across some curricular modules, they should be updated regularly and tailored to meet the needs of pharmacy practice in Jordan. A continuing pharmacy education program for practising pharmacists is also needed since the majority of Jordanian pharmacists work in community pharmacies which are considered the most accessible primary health care facilities.

\section{ACKNOWLEDGEMENT}

The authors would like to thank the staff and students of The Faculty of Pharmacy - University of Jordan for their cooperation in completing the survey. The authors wish to acknowledge the technical help provided by research assistants in data collection and entry.

\section{REFERENCES}

1. Pates R, McBride A, Li S, Ramadan R. Misuse of overthe-counter medicines: a survey of community pharmacies in a South Wales health authority. Pharm J 2002; 268: 179-182.

2. Albsoul-Younes A, Wazaify $M$, Yousef $A$, Tahaineh $L$. Abuse and Misuse of Prescription and Nonprescription Drugs Sold in Community Pharmacies in Jordan. Subst Use Misuse 2010; 45: 1319-1329.

3. Hughes $G$, McElnay $J$, Hughes $C$, McKenna $P$. Abuse/misuse of non-prescription drugs. Pharm World Sci 1999; 21: 251-255.

4. Wazaify $M$, Hughes $C, M c E l n a y ~ J$. The implementation of a harm minimisation model for the identification and treatment of over-the-counter drug misuse and abuse in community pharmacies in Northern Ireland. Patient Educ Couns 2006; 64: 136-141.

5. McCabe S, Teter C, Boyd C, Knightc J, Wechsler H. Nonmedical use of prescription opioids among U.S. college students: prevalence and correlates from a national survey. Addict Behav 2005; 30: 789-805.

6. McCabe S, Knight J, Teter C, Wechsler H. Nonmedical use of prescription stimulants among U.S. college students: prevalence and correlates from a national survey. Addiction 2005; 99: 96-106.

7. Teter C, McCabe S, Cranford J, Boyd C, Guthrie S. Prevalence and motivations for the illicit use of prescription stimulants in an undergraduate student sample. J Am Coll Health 2005; 53: 253-262.

8. Lord S, Downs G, Furtaw P, Chaudhuri A, Silverstein A, Gammaitoni A, Budman S. Nonmedical use of prescription opioids and stimulants among student pharmacists. J Am Pharm Assoc 2009; 49: 519-528.

9. Wenthur $C$, Cross $B$, Vernon V, Shelly J, Harth $B$, Lienhoop A, Madison N, Murawski M. Opinions and experiences of Indiana pharmacists and student pharmacists: The need for addiction and substance abuse education in the United States. Res Social Adm Pharm 2013; 9: 90-100.

Trop J Pharm Res, August 2015; 14(7): 1507 
10. Sweileh W, Arafat R, Al-Khyat L, Al-Masri D, Jaradat N. A pilot study to investigate over-the-counter drug abuse and misuse in Palestine. Saudi Med J 2004; 25 : 2029-2032.

11. Yousef A, Al-Bakri A, Bustanji Y, Wazaify M. SelfMedication Patterns in Amman, Jordan. Pharm World Sci 2008; 30: 24-30.

12. Al-Azzam SI, Al-Husein BA, Alzoubi F, Masadeh MM, AlHorani MA. Self-medication with antibiotics in Jordanian population. Int J Occup Med Environ Health 2007; 20: 373-380.

13. Sawair FA, Baqain ZH, Karaky AA, Eid RA. Assessment of Self-Medication of Antibiotics in a Jordanian Population. Med Princ Pract 2009; 18: 21-25.

14. Laure $P$, Kriebitzsch-Lejeune $A$. Retail pharmacists and doping in sports: Knowledge and attitudes. A national survey in France. Sci Sports 2000; 15: 141-146.

15. Auersperger I, Topic M, Maver P, Pusnik V, Osredkar J, Lainscak M. Doping awareness, views, and experience: A comparison between general practitioners and pharmacists. Wien. Klin Wochenschr 2012; 124: 32-38.

16. Saito $Y$, Kasashi K, Yoshiyama $Y$, Fukushima $N$, Kawagishi $T$, Yamada $T$, Iseki K. Survey on the attitudes of pharmacy students in Japan toward doping and supplement intake. Biol Pharm Bull 2013; 36: 305-310.

17. Koski R. Pharmacists' perceptions of controlled substance abuse in the rural upper peninsula of Michigan. J Am Pharm Assoc (2003) 2006; 46: 751 755.
18. Ponte C, Johnson-Tribino J. Attitudes and knowledge about pain among West Virginia pharmacists. J Am Pharm Assoc (2003) 2007; 47: 379-382.

19. Medication Therapy and Patient Care. Specific practice areas-statements. ASHP statement on the pharmacist's role in substance abuse prevention, education, and assistance. Am J Health Syst Pharm 2003; 60: 1995-1998.

20. Wazaify M, Albsoul-Younes A, Hakooz N. Improving pharmacy education at the Public Faculties of Pharmacy in Jordan: Students' experience and expectations. Pharm Educ 2010; 10: 107-113.

21. Loennechen T, Lind R, Mckellars S, Hudson S. Clinical pharmacy curriculum development in Norway: Pharmacists' expectations in the context of current European developments. Pharm Educ 2007; 7: 1926

22. Weiner A. Understanding the social needs of streetwalking prostitutes. Social Work 1996; 41: 97105.

23. Pharmacists' Defense Association in United Kingdom, 2004. [cited 2015 June 8]. Available from: http://www.the-pda.org/index.html

24. Matowe L, Al-Kandery A, Bihzad, S. Pharmacy in Kuwait. Am J Health Syst Pharm 2003; 60: 1591-1592.

25. Jousilahti $P$, Madkour S, Lambrechts $T$, Sherwin $E$. Diarrhoeal disease morbidity and home treatment practices in Egypt. Public Health 1997; 111: 5-10.

26. Haddad L, Shotar A, Umlauf M, Al-Zyoud S. Knowledge of Substance Abuse Among High School Students in Jordan. J Transcult Nurs 2010; 21: 143-150. 